\title{
TANTANGAN PENGEMBANGAN RUMAH SAKIT UMUM DAERAH MENJADI ORGANISASI PEMBELAJAR
}

\author{
Oleh: \\ Desita Rahayu *, Heru Nurasa' Ida Widianingsih, Josy Adiwisastra \\ *Email Korespondensi : desitanashattar@gmail.com
}

Program Doktor Ilmu Administrasi FISIP Universitas Padjadjaran

\begin{abstract}
ABSTRAK
Rumah Sakit diberbagai negara seperti Singapura, India, Thailand dan bahkan Malaysia telah membuktikan profesionalitasnya dengan berorientasi pada kebutuhan pelanggan seperti wisata medis. Orientasi pelayanan yang inovatif telah mampu menghasilkan devisa. Rumah Sakit di Malaysia dan bahkan Singapura telah masuk ke dalam 1000 Rumah Sakit terbaik di dunia. Kondisi sebaliknya yang terjadi di Indonesia, Rumah Sakit terbaik kita hanya bisa menduduki peringkat 3.858 dan belum mampu meraih kepercayaan publik, padahal dunia medis yang makin berkembang berbanding lurus dengan keinginan dan kebutuhan publik yang semakin kompleks. Oleh karena itu, Rumah Sakit di Indonesia (khususnya Rumah Sakit publik seperti Rumah Sakit umum daerah) harus melakukan perbaikan berkelanjutan. Namun, upaya perbaikan dengan mengembangkan diri menjadi Rumah Sakit publik yang pembelajar tidaklah mudah karena karakteristiknya sebagai organisasi publik. Teori Senge-disiplin kelima yang digunakan untuk mengidentifikasi permasalahan ini dengan cara berfikir sistem. Penelitian ini merupakan penelitian kualitatif dengan studi kasus yang bertujuan memberikan rekomendasi terhadap para pemangku kepentingan untuk mengidentifikasi tantangan Rumah Sakit publik agar dapat berkembang menjadi organisasi pembelajar yang mampu merespon kebutuhan publik akan pelayanan kesehatan yang berkualitas dan mengantisipasi atau mengatasi kondisi unlearning .
\end{abstract}

Kata Kunci: Rumah Sakit Umum Daerah, Organisasi Pembelajar, Kualitas Pelayanan Publik 
MIMBAR

JURNAL PENELITIAN SOSIAL DAN POLITIK

\section{A. Pendahuluan}

Tompkins (2005) mengatakan bahwa Rumah Sakit merupakan salah satu contoh organisasi kompleks yang di dalamnya terdiri dari struktur unit-unit yang berbedabeda, sedangkan Gortner, Mahler, \& Nicholson, (1997) menyebutkan bahwa organisasi yang kompleks bercirikan sizable, specialized, dan high interdependent. Karakteristik tersebut memang melekat pada Rumah Sakit yang terdiri dari berbagai unit yang di isi oleh tenaga-tenaga profesional bidang kesehatan sehingga pelayanan kesehatan yang dihasilkan merupakan kerjasama seluruh unit tersebut, mulai dari pos pendaftaran sampai dengan apotek.

Undang-Undang Nomor 44 Tahun 2009 / UU No. 44 Tahun 2009 tentang Rumah Sakit menyebutkan bahwa fungsi Rumah Sakit telah semakin berkembang tidak hanya pelayanan pengobatan, maupun pencegahan tetapi juga berfungsi sebagai sarana pendidikan sehingga menuntut kinerja Rumah Sakit yang lebih baik dan lebih profesional. Woodhams, et. al. (2012) mengatakan profesionalisme sektor kesehatan merupakan isu dunia yang telah direspon dengan baik oleh Rumah Sakit di berbagai negara seperti Singapura, India dan Thailand dan telah menjadi peluang industri kesehatan yang mendatangkan devisa melalui medical tourism (Crooks, Kingsbury, Snyder, \& Johnston, 2010). Rumah Sakit di negara-negara tersebut tengah fokus pada isu-isu kesehatan yang lebih kontemporer dengan sumber daya yang tidak hanya tenaga, alat, dan fasilitas kesehatan saja tetapi pengetahhuan sebagai salah satu sumber daya penting. Wilkesmann, et. al. (2009) mengatakan 'modern organizations cannot produce goods or services without knowledge.' Kemajuan Rumah Sakit di negara-negara tersebut tidak terlepas dari kemampuannya untuk terus menyesuaikan diri dengan teknologi dan pengetahuan kedokteran yang semakin canggih/modern sehingga profesionalisme sektor kesehatan semakin baik.

Rumah Sakit terbaik di Indonesia jauh tertinggal bila dilihat berdasarkan peringkat yang dirilis oleh Webometrics yang menyebutkan Rumah Sakit privat terbaik kita hanya menduduki posisi 3.858 , jauh tertinggal dibandingkan Malaysia, bahkan semakin tertinggal diibandingkan dengan Rumah Sakit publik milik Singapura yang telah masuk dalam 1.000 terbaik di dunia (http://hospitals.webometrics.info/, 2019). Posisi ini menunjukkan bahwa Rumah Sakit terbaik di Indonesia kalah bersaing bahkan Rumah Sakit Malaysia telah meraih kepercayaan para pensiunan dari Jepang yang menginginkan pelayanan kesehatan hari tuanya dilakukan di sana (Kohno et al., 2016).

Rumah Sakit Malaysia dan Singapura telah membuktikan profesionalitasnya sehingga tidak hanya mendatangkan devisa tapi menjaga eksistensi/ masa depannya, seperti yang diungkapkan oleh Ikujiro Nonaka dalam Starkey (1996) bahwa masa depan organisasi ditentukan oleh kemampuan menciptakan pembaharuan pengetahuan dan menterjemahkannya menjadi inovasi baik produk maupun proses.

Tuntutan publik adalah pelayanan kesehatan yang berkualitas tinggi yang dapat dilakukan melalui perbaikan berkelanjutan (Wind \& Van Harten, 2017; Larisch, AmerWåhlin, \& Hidefjäll, 2016). RSUD dapat mengadopsi teori organisasi pembelajar agar dapat melakukan perubahan untuk terus eksis dalam persaingan bisnis kesehatan. Teori organisasi pembelajar memang lahir dari organisasi privat (Marquardt, 2002; Heijden, 2005; Senge, 1990) namun pergeseran konsep belajar yang tidak hanya untuk organisasi privat tetapi juga organisasi publik seperti yang disebutkan oleh berbagai ahli seperti Salge \& Vera (2012), Khan (2010), dan Maden (2012). Teori ini dapat diadopsi oleh organisasi publik yang sudah harus dijalankan seperti 'bisnis' (Thompkins, 2005) khususnya bila dikaitkan dengan upaya peningkatan kinerja namun harus dimodifikasi agar sesuai dengan konteks manajemen publik. Namun demikian merubah RSUD menjadi organisasi pembelajar tidaklah mudah karena ada beberapa karakteristiknya sebagai organisasi publik yang menyebabkannya tidak sefleksibel organisasi privat dalam belajar.

\section{B. Metode Penelitian}

Artikel ini merupakan bagian dari penelitian (disertasi) dengan topik manajemen kualitas pelayanan di RSUD dengan fokus pada multi stakeholder, rancangan penelitiannya adalah kualitatif. 
Creswell (2014) menyebutkan bahwa rancangan kualitatif merupakan metode untuk mengeksplorasi dan memahami makna yang oleh sejumlah individu atau kelompok orang dianggap berasal dari masalah sosial atau kemanusiaan. Metode inilah yang digunakan dalam penelitian tersebut dengan strategi studi kasus yang digunakan dalam mengurai permasalahan pelayanan kesehatan dengan lokus RSUD. Oleh karena itu, tujuan dari artikel ini adalah mengidentifikasi berbagai tantangan ataupun kendala yang harus dihadapi oleh RSUD dalam rangka meningkatkan kualitas pelayanan dengan menjadi organisasi pembelajar. Analisis ini diharapkan dapat menjadi rekomendasi yang berlandaskan berbagai konsep teoritis yang terstruktur dengan mengemukakan berbagai argumentasi terkait upaya pemecahan masalah yang ada.

\section{HASIL DAN PEMBAHASAN}

Upaya perbaikan dengan merubah atau mengembangkan RSUD menjadi organisasi pembelajar harus dilihat secara holistik dengan menggunakan disiplin berfikir sistem, dimana kondisi atau kemampuan RSUD sebagai sebuah organisasi menjadi bahan dasar penting. Oleh sebab itu, perlu dipahami karakteristik RSUD sebagai organisasi publik secara rinci. Christensen, et.al. (2007) menyebutkan salah satu karakteristik organisasi publik adalah do not operate within a free and competitive market. Sementara Graham Allison dalam Christensen, et.al. (2007) juga menyebutkan ada 3 (tiga) unsur penting yang membedakan organisasi publik dan privat, yaitu :

1. Kepentingan (interest) publik dibatasi oleh norma dan nilai dengan lebih banyak pertimbangan demokratis, nilai konstitusi, dan kesejahteraan publik.

2. Arus amanah kepada rakyat dan pemilihnya.

3. Keterbukaan, transparansi, keadilan, tidak terpisahkan dan bisa diprediksi.

Ketiga unsur tersebut didukung pula oleh Tompkins (2005) yang menyebutkan secara rinci karakteristik organisasi publik seperti RSUD dan konsekuensinya terhadap aktivitas manajerial yang berbeda dengan organisasi privat, seperti Pada tabel 1 berikut:
Tabel 1 Karakteristik Organisasi Publik dan Privat

\begin{tabular}{|c|c|c|}
\hline $\begin{array}{l}\text { Karakt } \\
\text { eristik }\end{array}$ & $\begin{array}{l}\text { Organisasi } \\
\text { Publik }\end{array}$ & $\begin{array}{l}\text { Organisasi } \\
\text { Privat }\end{array}$ \\
\hline $\begin{array}{l}\text { Fragme } \\
\text { nted } \\
\text { authori } \\
\text { ty }\end{array}$ & $\begin{array}{l}\text { Ada tingkatan } \\
\text { kekuasaan } \\
\text { dengan lingkup } \\
\text { kewenangan } \\
\text { masing-masing, } \\
\text { sehingga } \\
\text { manajer publik } \\
\text { tidak bebas. }\end{array}$ & $\begin{array}{l}\text { Kendali } \\
\text { tunggal } \\
\text { sehingga } \\
\text { manajer lebih } \\
\text { bebas } \\
\text { menentukan } \\
\text { tujuan, misi, } \\
\text { dan } \\
\text { penyesuaian } \\
\text { metode. }\end{array}$ \\
\hline $\begin{array}{l}\text { Respon } \\
\text { sivitas, } \\
\text { aksesib } \\
\text { ilitas, } \\
\text { dan } \\
\text { keterbu } \\
\text { kaan } \\
\text { penga } \\
\text { mbilan } \\
\text { keputu } \\
\text { san }\end{array}$ & $\begin{array}{l}\text { Manajer tidak } \\
\text { bebas } \\
\text { menentukan } \\
\text { outcome. Proses } \\
\text { lebih lama dan } \\
\text { kompleks. } \\
\text { Diawasi oleh } \\
\text { media, } \\
\text { kelompok } \\
\text { kepentingan dan } \\
\text { partai }\end{array}$ & $\begin{array}{l}\text { Manajer lebih } \\
\text { bebas } \\
\text { mengambil } \\
\text { keputusan } \\
\text { sehingga lebih } \\
\text { cepat. }\end{array}$ \\
\hline $\begin{array}{l}\text { Penent } \\
\text { uan } \\
\text { Tujuan }\end{array}$ & $\begin{array}{l}\text { Dipengaruhi } \\
\text { janji politik dan } \\
\text { lebih abstrak } \\
\text { sehingga lebih } \\
\text { sulit } \\
\text { menentukan } \\
\text { kinerja dan } \\
\text { mengukur } \\
\text { keberhasilan }\end{array}$ & $\begin{array}{l}\text { Penentuan } \\
\text { tujuan yang } \\
\text { lebih konkrit } \\
\text { seperti } \\
\text { pertumbuhan, } \\
\text { penjualan, } \\
\text { keuntungan. } \\
\text { Akibatnya } \\
\text { lebih mudah } \\
\text { diukur. }\end{array}$ \\
\hline $\begin{array}{l}\text { Kendala } \\
\text { Prosedural }\end{array}$ & $\begin{array}{l}\text { Bebas bertindak } \\
\text { selama tidak } \\
\text { bertentangan } \\
\text { dengan otoritas } \\
\text { kewenangan } \\
\text { (prosedural). }\end{array}$ & $\begin{array}{l}\text { Bebas dari } \\
\text { kelompok } \\
\text { kepentingan } \\
\text { sehingga } \\
\text { tindakannya } \\
\text { tidak dibatasi } \\
\text { aturan (lebih } \\
\text { bebas). }\end{array}$ \\
\hline $\begin{array}{l}\text { Kendal } \\
\text { a } \\
\text { politis }\end{array}$ & $\begin{array}{l}\text { Pengambilan } \\
\text { keputusan } \\
\text { dipengaruhi } \\
\text { lingkungan } \\
\text { politik oleh } \\
\text { tekanan luar dan } \\
\text { dampak politik }\end{array}$ & $\begin{array}{l}\text { Berdasarkan } \\
\text { analisis biaya } \\
\text { manfaat, } \\
\text { perhitungan } \\
\text { rasional } \\
\text { (efisiensi dan } \\
\text { efektivitas). }\end{array}$ \\
\hline
\end{tabular}

Sumber : diolah dari Tompkins (2005) 
MIMBAR

JURNAL PENELITIAN SOSIAL DAN POLITIK

Tompkins (Tompkins, 2005) menggunakan istilah bureau untuk organisasi publik dan istilah firms untuk organisasi privat. Ia menyatakan bahwa perbedaan utama antara bureau dan firm adalah bahwa organisasi publik ada dalam rangka menjalankan hukum. Adanya perbedaan tersebut mengakibatkan karakteristik organisasi publik menjadi berbeda dengan organisasi privat.

Adanya beberapa karakteristik organisasi publik yang tidak mendukung terwujudnya organisasi pembelajar, bukan berarti organisasi publik seperti RSUD tidak dapat berubah dan berkembang ke arah tersebut. Hal ini didukung oleh pendapat Khan (2010) yang mengatakan organisasi publik pun dapat menjadi learning organisasi. Senge (1990) juga mengatakan learning organisasi menurutnya tidak muncul dengan sendirinya tetapi melalui kolektif learning yang diawasi oleh pemimpin yang berkarakter persuasif, berkomitmen kuat, dan terbuka terhadap learning berkelanjutan.

Berfikir sistem dalam melihat karakteristik dan kapabilitas RSUD secara keseluruhan, harus dilanjutkan dengan kedisiplinan dalam berbagi visi, model mental, pembelajaran tim dan keahlian pribadi untuk mengetahui potensinya. Lima disiplin ini dibahas secara rinci oleh Khan (2010) yang menyatakan bahwa penerapan model ini pada sektor publik seperti RSUD harus memperhatikan kendala-kendala yang dapat mengakibatkan organisasi publik tidak dapat learning sehingga harus diatasi, yaitu :

a. Pada disiplin System thinking, organisasi publik terbagi ke dalam wilayah kerja yang cenderung kaku (seperti yang telah disebutkan sebelumnya terkait karakteristik RSUD sebagai organisasi publik yang berbeda dengan organisasi privat), padahal untuk dapat merespon tuntutan dari luar organisasi, RSUD harus lebih fleksibel. Hal ini senada dengan pernyataan Ginting, Susanti, \& Sumaryana (2018) bahwa salah satu kondisi yang dapat menjadi penghalang interaksi antara pemerintah, publik dan privat adalah struktur pemerintah yang bersifat hirarkis dan fungsional. b. Pada disiplin shared vision, menurut Khan (2010) organisasi publik cenderung tidak mampu menentukan visi yang jelas; visi organisasi publik masih berkaitan dengan memperoleh, memanfaatkan dan mempertahankan kekuasaan. Kondisi ini pun terjadi di RSUD yang memang merupakan organisasi publik sektor kesehatan. RSUD di Indonesia merupakan bagian dari UU No. 40 tahun 2004 tentang SJSN yang bertujuan mewujudkan UHC di tahun 2019 atau Indonesia Sehat 2019, dan untuk mewujudkan tujuan tersebut RSUD harus melaksanakan hak dan kewajiban dengan baik seperti yang tercantum dalam pasal 29 UU NO. 40 tahun 2009. Visi Indonesia sehat 2019 tidak dapat diwujudkan oleh satu atau dua Rumah Sakit saja tetapi seluruh RSUD dan RS privat, namun sayangnya data (Kementrian Kesehatan RI, 2016) menunjukkan bahwa sampai dengan tahun 2016 dari 190 Rumah Sakit umum yang ditargetkan terakreditasi baru 59 saja. Hal ini berarti RSUD yang kondisinya sesuai dengan kebutuhan mewujudkan visi tersebut masih sangat sedikit.

RSUD di Indonesia juga mengalami berbagai permasalahan lain yang dapat menghambat upayanya untuk menjadi learning organisasi. Rasio tenaga kesehatan yang masih belum berimbang dengan jumlah penduduk, serta sebenanya yang tidak merata (Meliala, 2014). Kondisi ini telah lama terjadi sejak Indonesia merdeka (Heywood \& Harahap, 2009). Pusat Data dan Informasi (Pusdatin) Kemenkes RI mempublikasikan pernyataan kekurangan tenaga kesehatan dan permasalahan distribusinya melalui data tahunan mengenai capaian rasio tenaga kesehatan di Indonesia yang secara umum ternyata masih belum berimbang dengan jumlah penduduknya : 
MIMBAR

JURNAL PENELITIAN SOSIAL DAN POLITIK

Tabel 2.Target Rasio Tenaga Kesehatan

Indonesia Tahun 2014 dan Indonesia

Sehat Tahun 2019, serta Profil Kesehatan Indonesia Tahun 2015

\begin{tabular}{|l|c|c|c|}
\hline $\begin{array}{l}\text { Tenaga } \\
\text { Keseha }\end{array}$ & $\begin{array}{c}\text { Target } \\
\text { Rasio } \\
\text { Indikator } \\
\text { Indonesia } \\
\text { Sehat 2014 }\end{array}$ & $\begin{array}{c}\text { Kondisi / } \\
\text { Profil } \\
\text { Kesehatan } \\
\text { Indonesia } \\
2015\end{array}$ & $\begin{array}{c}\text { Target } \\
\text { Rasio } \\
\text { Indonesi } \\
\text { a Sehat } \\
2019\end{array}$ \\
\hline $\begin{array}{l}\text { Dokter } \\
\text { umum }\end{array}$ & 40 & 16,06 & 45 \\
\hline $\begin{array}{l}\text { Dokter } \\
\text { gigi }\end{array}$ & 11 & 4,57 & 13 \\
\hline $\begin{array}{l}\text { Perawa } \\
\text { t }\end{array}$ & 158 & 87,65 & 180 \\
\hline Bidan & 100 & 43,74 & 120 \\
\hline
\end{tabular}

Sumber : (Kementrian Kesehatan RI, 2016)

Ket : perbandingan per 100.000 penduduk

Bahkan sampai dengan tahun 2015, Indonesia masih belum mampu mencapai target tahun sebelumnya yaitu 2014 . Padahal, target 40 dokter umum, 11 dokter gigi, 158 perawat dan 100 bidan per 100.000 penduduk tersebut indikator kecukupan sektor kesehatan di tahun 2014 yang masih belum bisa dicapai bahkan pada tahun 2015 . Salah satu implikasi dari kondisi tersebut adalah adanya RSUD yang masih kekurangan tenaga kesehatan seperti dokter maupun dokter spesialis penunjang seperti yang dipublikasikan oleh Kemenkes RI tahun 2016 melalui Badan Pengembangan dan Pemberdayaan Sumber Daya Manusia Kesehatan bahwa ada banyak Rumah Sakit umum di Indonesia yang masih belum memenuhi standar minimal kebutuhan dokter spesialis dasar dan spesialis penunjang (Kementrian Kesehatan RI, 2016). Keterbatasan SDK ini mengakibatkan pelayanan kesehatan yang seharusnya dilakukan oleh tenaga profesional tertentu digantikan oleh tenaga profesional dengan kualifikasi lebih rendah seperti dokter umum atau bahkan perawat.

c. Ada pula kendala yang harus dihadapi dalam melaksanakan disiplin personal mastery dimana organisasi pemerintah seperti RSUD cenderung harus mengikuti standar dan prsedur rutin. Ada aturan dan regulasi yang dibuat dalam rangka menghindari nepotisme, diskriminasi, keberpihakan politik, serta bias. Sehingga reward dan promosi sangat sedikit dalam mendorong pegawai. Tidak hanya pelaksanaan reward di RSUD, personal mastery pun terkait dengan masalah medical fee. Medical fee yang rendah menyebabkan sebagian besar dokter spesialis yang telah bekerja di RSUD tersebut juga membuka praktek pribadi mencari penghasilan tambahan di daerah dimana mereka dipekerjakan atas seizin pemerintah (Heywood \& Harahap, 2009). Padahal kondisi ini berpengaruh terhadap jam kerja di rumah sakit, namun demikian pimpinan Rumah Sakit tetap memberikan kelonggaran / fleksibilitas jam kerja yang bisa disesuaikan (Meliala, 2014). Bahkan berdasarkan hasil penelitian Heywood dan Harahap (yang lebih mengejutkan) disebutkan ada kurang lebih $60 \%$ (enam puluh persen) perawat yang merupakan pegawai RSUD atau PNS di institusi pelayanan kesehatan lain juga membuka praktek pribadi secara ilegal. Sehingga wajar saja bila kita kerap kali mendengar keluhan pasien terkait dokter atau tenaga kesehatan yang datang terlambat atau bahkan tidak hadir saat jam prakteknya di RSUD, yang berakibat pada terhambatnya pelayanan kesehatan seperti yang terjadi di RSUD Curup (RMOL Bengkulu, 2016).

d. Pada disiplin model mental, menurut Khan organisasi pemerintah terdapat departemen-departemen yang terpisah yang sulit untuk disatukan dalam proses learning secara bersama, dan ini juga terjadi di RSUD.

e. Pada disiplin team learning, menurut Khan organisasi pemerintah lemah (hal ini dipicu oleh empat kendala sebelumnya). Team learning juga dapat terkait penggunaan teknologi baru dimana Kasra, Nur dan Aljunid (2012) mengatakan penggunaan teknologi baru dalam pelayanan kesehatan merupakan salah satu penyebab peningkatan biaya kesehatan di Indonesia, dan hal ini berakibat buruk terhadap aksesibilitas pelayanan kesehatan masyarakat miskin. Rumah Sakit publik khususnya Rumah Sakit Umum Daerah (RSUD) dan tenaga keseharan harus terus update 
MIMBAR

JURNAL PENELITIAN SOSIAL DAN POLITIK

perkembangan teknologi kedokteran, dan pemanfaatan teknologi baru menyebabkan peningkatan biaya kesehatan, sementara itu, pasca pemberlakuan UU No. 40/2004 sudah bisa dipastikan segmen pelanggan RSUD adalah peserta Jaminan Kesehatan Nasional (JKN) yang pengelolaan pembayarannya dilakukan oleh BPJS Kesehatan dengan sistem paket (Indonesia Case Base Groups ANA-CBGs). Adanya sistem ini menyebabkan RSU tidak mungkin 'untung besar', namun tetap dituntut untuk menggunakan teknologi kesehatan yang update. Jadi, RSUD di Indonesia menghadapi dilema dituntut bekerja profesional, terus update perkembangan dunia medis yang beresiko terhadap peningkatan biaya namun tetap harus berjiwa sosial (non profit oriented) seperti yang disebutkan dalam UU No.44/2009 tentang Rumah Sakit.

Adanya lima kendala yang juga dihadapi RSUD untuk dapat menjadi learning organisasi harus diatasi menurut Pedler dalam Khan (2010) dengan cara :

1. Membuat strategi yang mendukung partisipasi dalam aktivitas learning,

2. Memperhatikan umpan balik yang berasal dari keuangan, proses kontrol dan akibatnya terhadap kebijakan dan pengambilan keputusan,

3. Membuat struktur organisasi yang fleksibel agar perubahan dan pergantian dapat dilakukan

4. Mendorong budaya berbagi pengalaman keberhasilan dan kegagaln learning

5. Adanya sistem insentif yang medorong para individu dalam organisasi untuk mengembangkan diri.

Berbagai permasalahan yang menghambat upaya RSUD menjadi organisasi yang pembelajar seharusnya sudah semakin dapat di atasi oleh pemerintah, karena alokasi anggaran kesehatan yang persentasenya terus mengalami peningkatan dan telah tercukupi mulai tahun 2016 seperti yang tampak pada tabel 3. berikut :
Tabel 3.

Alokasi Anggaran Kemenkes dari APBN
\begin{tabular}{|l|l|}
\hline APBN Tahun & Jumlah anggaran \\
\hline 2008 & Rp 18,56 Triliun \\
\hline 2009 & Rp 20,93 Triliun \\
\hline 2013 & Rp 38,61 Triliun \\
\hline 2014 & Rp 46,459 Triliun \\
\hline 2015 & $\begin{array}{l}\text { Rp 71,1 Triliun (3,5\% } \\
\text { dari APBN) }\end{array}$ \\
\hline 2016 & $\begin{array}{l}\text { Rp 109 Triliun (5\% dari } \\
\text { APBN) }\end{array}$ \\
\hline
\end{tabular}

Sumber :1) Kementerian Kesehatan, 2019

2) Kementrian Kesehatan, 2016)

Kecukupan anggaran kesehatan seharusnya menjadi momentum perubahan atau pengembangan RSUD di Indonesia untuk dapat lebih responsif dan mampu menjawab tutntutan perkembagan dunia kesehatan. UU No. 44 tahun 2009 menyebutkan bahwa Rumah Sakit merupakan organisasi yang memberikan pelayanan kesehatan mulai dari rawat inap, rawat jalan, sampai dengan gawat darurat. Definisi tersebut hampir sama dengan definisi yang dinyatakan oleh WHO (Expert Committee On Organization Of Medical Care) yang menyebutkan Rumah Sakit sebagai kesatuan organisasi medis dan sosial yang berfungsi menyediakan pelayanan kesehatan lengkap. Rumah Sakit juga merupakan pusat pelatihan bagi para pekerja dan para peneliti bidang kesehatan.

Pasal 29 UU No. 40/2009 menyebutkan tentang 20 (dua puluh) kewajiban Rumah Sakit mulai dari penyediaan informasi yang benar tentang pelayanan kesehatan, pemberian informasi yang benar, pelayanan kesehatan, pelayanan gawat darurat, sampai dengan pemberlakuan kawasan tanpa rokok di rumah sakit. Ayat pada pasal tersebut juga menyebutkan kewajiban Rumah Sakit untuk menjalankan fungsi sosial melalui pemberian fasilitas pelayanan kesehatan pasien miskin, pelayanan gawat darurat tanpa uang muka, ambulan gratis sampai dengan misi kemanusiaan lainnya. Fungsi sosial Rumah Sakit yang dimaksud pada ayat tersebut harus terlaksana dengan tetap menjaga standar mutu kesehatan sebagai acuan dalam melayani pasien (seperti tercantum pada ayat selanjutnya). 


\section{E. SIMPULAN}

RSUD di Indonesia mengalami ketertinggalan bila dibandingkan dengan berbagai Rumah Sakit di negara tetangga, oleh sebab itu perbaikan dan pembaharuan harus dilakukan dengan cara bermetamorfosa menjadi learning organisasi. Namun upaya menjadi learning organisasi menghadapi berbagai tantangan, salah satunya adalah karakteristik organisasi publik tidak sefleksibel organisasi privat dalam melakukan aktivitas learning. Oleh sebab itu, dengan mengidentifikasi tantangan untuk menjadi learning organisasi dalam hal : berpikir sistem, model mental, personal mastery, shared vision, dan team learning maka stakeholder dapat melakukan antisipasi ataupun upaya mengatasi keadaan tersebut sehingga aktivitas learning tetap dapat dilakukan dengan tujuan perbaikan dan pembaharuan pelayanan kesehatan menuju UHC tahun 2019.

\section{DAFTAR PUSTAKA}

Choo, C. W. (2006). The knowing organization as learning organization Use Information to Construct Meaning, Create Knowledge, and Make Decisions. (Second). New York: Oxford University Press. https://doi.org/10.1108/EUM0000000 005482

Christensen, T., Laegreid, P., Roness, P. G., \& Rovik, K. A. (2007). Organization Theory and the Public Sector. London and New York: Routledge Taylor \& Francis Group.

Clegg, S. R. (1990). Modern Organizations Organization Studies in the Postmodern World. London: SAGE Publications.

Creswell, J. W. (2014). Research Design_ Qualitative, Quantitative, and Mixed Methods Approaches (fourth). Los Angeles: SAGE.

Crooks, V. A., Kingsbury, P., Snyder, J., \& Johnston, R. (2010). What is known about the patient's experience of medical tourism? A scoping review. BMC Health Services Research. https://doi.org/10.1016/0006291X(73)91125-X

Dekkers, R. (2005). ( $R$ ) Evolution Organizations and The Dinamics of The Environment. New YOrk: Springer.
Drori Gili, W., M. J., \& Hojyu, H. (2006). Globalization and Organization. New York: Oxford University Press.

Gibson, J. L., Ivancevich, J. M., Donelly Jr, J. H., \& Konopaske, R. (2012). Organizations Behaviour, Structure, Processes. (Fourteenth, Vol. 91). New YOrk: McGraw-Hill Irwin.

Ginting, L. M., Susanti, E., \& Sumaryana, A. (2018). IMPLEMENTASI PELAYANAN TERPADU SATU PINTU NON-PERIZINAN INDEKS KEPUASAN MASYARAKAT. RESPONSIVE, 1(2), 45-55.

Gortner, H. F., Mahler, J., \& Nicholson, J. B. (1997). Organization Theory: a public perspective (2nd ed.). Orlando: Harcourt Brace College Publishers.

Heywood, P., \& Harahap, N. P. (2009). Health facilities at the district level in Indonesia. Australia and New Zealand Health Policy. https://doi.org/10.1186/1743-8462-613

http://hospitals.webometrics.info/. (2019). webometrics.pdf. Retrieved from http://hospitals.webometrics.info/

Kasra, K., Nur, A. M., \& Aljunid, S. M. (2012). The impact of Casemix system on quality of patient care in a Class B hospital in west Sumatera Province, Indonesia. BMC Health Services Research, 12(November). https://doi.org/10.1186/1472-6963-12S1-O9

Kementrian Kesehatan RI. (2016). 2015 Profil Kesehatan Indonesia. Kementerian Kesehatan RI.

Kesehatan, K. P. P. dan J. (2019). Rencana aksi kegiatan Pusat Pembiayaan dan Jaminan Kesehatan 2015 sd 2019. Retrieved from http://www.depkes.go.id/resources/do wnload/LAKIP ROREN/1 perencanaan kinerja/RAK PPJK.pdf

Khan, I. A. (2010). Knowledge Groups : A Model for Creating Synergy Across the Public Sector. Public Organization Review, $139-152$. https://doi.org/10.1007/s11115-0090101-z

Kohno, A., Musa, G., Daliana, N., Farid, N., Aziz, N. A., \& Nakayama, T. (2016). Issues in healthcare services in Malaysia as experienced by Japanese 
retirees. BMC Health Services Research, 1-11. https://doi.org/10.1186/s12913-0161417-3

Larisch, L. M., Amer-Wåhlin, I., \& Hidefjäll, P. (2016). Understanding healthcare innovation systems: the Stockholm region case. Journal of Health, Organisation and Management, 30(8), 1221-1241. https://doi.org/10.1108/JHOM-042016-0061

Maden, C. (2012). Transforming Public Organizations into Learning Organizations: A Conceptual Model. Public Organization Review, 71-84. https://doi.org/10.1007/s11115-0110160-9

Marquardt, M. J. (2002). Building the Learning Organization (2nd ed.). Palo Alto: Davies Black Publishing.

Meliala, A. (2014). Distribution and engagement of specialist doctors in public hospitals in Indonesia. BMC Public

Health. https://doi.org/10.1186/1471-2458-14S1-O15

Pfeffer, J. (1997). New Directions for Organization Theory. New York: Oxford University Press. https://doi.org/10.1360/zd-2013-43-61064

RMOL Bengkulu. (2016). Puluhan Pasien Poli Anak RSUD Curup Terlantar. Bengkulu. Retrieved from http://www.rmolbengkulu.com/read/2 016/03/03/172/Puluhan-Pasien-PoliAnak-RSUD-Curup-Terlantar-

Robbins, S. P., Judge, T. A., \& Breward, K. E. (2016). Essentials of Organizational Behaviour. Ontario: Pearson Canada Inc.

Salge, T. O., \& Vera, A. (2012). Benefiting from Public Sector Innovation: The Moderating Role of Customer and Learning Orientation. Public Administration Review, 72(4), 550559. https://doi.org/10.1111/j.15406210.2012.02529.x

Senge, P. (1990). The fifth discipline: Strategies and tools for building a learning organizatio.

Smiraglia, R. P. (2014). The Elements of knowledge organization. Milwaukee: Springer. https://doi.org/10.1007/978-
3-319-09357-4

Soklaridis, S. (2014). Improving hospital care: are learning organizations the answer? Journal of Health, Organisation and Management, 28(6). https://doi.org/10.1108/JHOM-102013-0229

Starkey, K. (1996). How Organization Learn. London: International Thomson Business Press.

Thompkins, J. R. (2005). Organization Theory and Public Management. Belmont: Clack Baxter.

Tompkins, J. (2005). Organization Theory and Public Management. Belmont: Clark Baxter. https://doi.org/http://dx.doi.org/10.100 1/archotol.134.6.625

Tsai, Y. (2014). Learning organizations, internal marketing, and organizational commitment in hospitals. BMC Health Services Research, 14(1). https://doi.org/10.1186/1472-6963-14152

Van der Heijden, K. (2005). The Art of Strategic Conversation. John Wiley \& Sons.

https://doi.org/10.1107/S00218898000 99751

Wilkesmann, U., Wilkesmann, M., \& Virgillito, A. (2009). The absence of cooperation is not necessarily defection: Structural and motivational constraints of knowledge transfer in a social dilemma situation. Organization Studies, 30(10), 1141-1164. https://doi.org/10.1177/017084060934 4385

Wind, A., \& Van Harten, W. H. (2017). Benchmarking specialty hospitals, a scoping review on theory and practice. BMC Health Services Research, 17(1), 1-20. https://doi.org/10.1186/s12913017-2154-y

Woodhams, V., Lusignan, S. de, Mughal, S., Head, G., Debar, S., Desombre, T., Sharifi, H. Al. (2012). Triumph of hope over experience: learning from interventions to reduce avoidable hospital admissions identified through an Academic Health and Social Care Network. BMC Health Services Research, 12(June), 153. 